\title{
TARIFA SOCIAL DA ÁGUA NO BRASIL: REFLEXÕES SOBRE AVANÇOS E LACUNAS
}

\section{SOCIAL TARIFF FOR DRINKING WATER IN BRAZIL: REFLECTIONS ON ADVANCES AND GAPS}

\begin{abstract}
Gesmar Rosa dos Santos
Doutor em Desenvolvimento Sustentável pela Universidade de Brasília (UnB). Pesquisador do Instituto de Pesquisa Econômica Aplicada (IPEA). Realiza estudos e análises de políticas públicas de meio ambiente, água e saneamento.
\end{abstract}

E-mail: gesmarsantos@gmail.com

\section{RESUMO}

Este artigo discute o aprimoramento da Tarifa Social da Água (TSA) e de medidas semelhantes adotadas no Brasil como forma de garantir o acesso à água como direito humano. Abordam-se aspectos legais de promoção e sustentação econômica do benefício de acesso à população carente, com o objetivo de fomentar a discussão sobre a necessidade de avanços na definição das responsabilidades do poder público, de prestadores de serviços e órgãos reguladores, para ampliar a cobertura desse direito em todo o País. Foi realizada pesquisa exploratória documental, da legislação e bibliográfica acerca da institucionalização, situação atual e lacunas da TSA. Verificou-se evolução positiva nas diretrizes presentes nas normas, assim como iniciativas estaduais relevantes; contudo, o instrumento é dependente de ações discricionárias de dirigentes políticos, tem critérios restritivos ao acesso, necessita maior transparência e avaliação criteriosa conjunto com a sociedade. São apontadas novas questões para fomentar o debate no tema.

\begin{abstract}
This article discusses the improvement of the Tarifa Social da Água (Social Drinking Water Tariff) - TSA) and similar policies adopted in Brazil to guarantee access to drinking water as a human right. We discuss institutional, legal, and economic conditions to support the access to the vulnerable population. The purpose of this article is encourage discussion on the progress about responsibilities of public authorities, service providers and regulatory bodies, in order to expand coverage this right throughout the country. Exploratory documentary, legislation and bibliographic research was carried out on the current situation and gaps of the TSA. We verified a positive evolution in the guidelines and norms, as well as relevant state initiatives; however, the instrument still depending on the discretionary actions of political leaders, has restricted access criteria, needs greater transparency and careful assessment by society. New issues are pointed out to encourage debate on this subject.
\end{abstract}

Palavras-chave: Palavras-chave: Tarifa Social. Legislação. Regulação. Saneamento.

Key words: Social Tariff. Legislation. Regulation. Drinking Water.

\section{INTRODUÇÃO}

Tendo em conta as estimativas da Organização Mundial de Saúde (OMS) e de pesquisas independentes sobre a importância do saneamento como saúde, o Brasil, por meio da Lei $\mathrm{n}^{\circ}$. 11.445/2007 (Política Nacional de Saneamento Básico - PNSB), reconhece aspectos importantes da água como direito humano. A economia de gastos com a saúde também é destacada no âmbito de estudos da Organização Mundial da Saúde, como mostra WHO (2009) e Hulton e WHO (2012). Para este último, a estimativa de redução de até 4,3 unidades monetárias com gastos em saúde deve induzir ações de saneamento básico, sendo que na América Latina e Caribe estimaram em 5,2 unidades esse "retorno". 
Araújo e Bertussi (2018) apontam a universalização do acesso à água e esgotamento sanitário para reduzir internações e a mortalidade por infecções gastrointestinais, além de dar condições para as pessoas diminuírem os afastamentos do trabalho, condição necessária para a manutenção e até aumento da produtividade e da massa salarial. Dessa forma, a relevância do tema supera os arranjos de ação estatal que viabilizam obras e prestação de serviços, estando listado como o Objetivo de Desenvolvimento Sustentável 6 (ODS 6) das Nações Unidas, acordo do qual o Brasil é signatário e que propaga a universalização do acesso à água como direito humano.

Santos (2020) destaca a importância da tarifa social da água (TSA) para promover o acesso à água como bem essencial à saúde, à vida, devendo somar-se à efetivação de outras medidas de aumento da acessibilidade econômica aos serviços. Leis, acordos de governança e arranjos tarifários já atribuem responsabilidades dos diversos níveis de governo (União, estados e municípios), prestadores de serviços, agências reguladoras na implementação da TSA. Embora em forma de diretrizes, a PNSB já atribui papéis a esse conjunto de atores; contudo, a tarifa social não se encontra universalizada no País (Brasil, 2019), havendo poucos estados com sólida implementação.

A grande dificuldade de municípios endividados em investir no saneamento (Kuwajima et al., 2020), aliado ao aumento do desemprego e da renda do trabalho são fatores que exigem baratear o acesso à água para a população mais pobre. Essa indicação de promover a acessibilidade econômica, prevista nos ODS e na fundamentação da ONU de água como direito humano implica também difundir o papel do saneamento no contexto socioambiental, inclusivo, com especial atenção às mulheres e crianças. Portanto, a compreensão de preço reduzido deve alcançar a cidade e o campo, como apontam estudos oficiais e acadêmicos recentes (Brasil, 2018; 2019; Heller; Buss; Barraqué, 2016; Santos e Santana, 2020). Para isso, as soluções com o timbre "social" (a exemplo da TSA) devem se estender ao saneamento rural, com subsídios de formatos regionais ou locais e características próprias. Entretanto, Brasil (2019) aponta diversas lacunas inclusive de ordem legal, operacional, de abrangência e de público-alvo -, na implementação da tarifa social na maioria dos estados.

Dessa forma, o objetivo deste artigo é fomentar a discussão sobre a necessidade de avanços na definição das responsabilidades da União, estados, municípios e prestadores de serviços, bem como órgãos reguladores, para garantir a água como direito humano. Em razão do curto espaço, deixam-se também questões em aberto para fomentar pesquisas e debates acerca das formas de viabilizar a tarifa social para tornar claras as atribuições que garantam a água como direito.

Um desafio adicional colocado para toda a sociedade é a sinalização dada pelo recente debate e mudanças na legislação (Lei 14.026/2020) de que o setor de saneamento passa, cada vez mais, a ser direcionado como um ramo de atividades econômicas. Essa perspectiva aponta os negócios (de empresas públicas e privadas) como espaço central na determinação de formas de prover serviços. Nessa condição, a hipótese que permeia este texto é a de que a regulamentação deve ser direta e objetiva no sentido de dar garantias de acesso e continuidade dos serviços, uma vez que o mercado é incapaz e desinteressado em questões como a TSA.

\section{METODOLOGIA}

Utiliza-se de revisão da bibliografia, com sistematização e análise também de documentos e normas sobre as regras de prestação de serviços e responsabilidades dos agentes públicos e privados que atuam no saneamento. Destacam-se os aspectos da regulação ao nível de agências e provimento de recursos que podem viabilizar a TSA, obtidos por meio de busca nos respectivos sítios na internet, relatórios anuais e no marco legal pertinente. Verificou-se o tipo de instrumento legal de implementação da TSA, bem como as formas de cálculo e exigências de elegibilidade.

Para o cálculo aproximado do nível de redução costumeiramente praticada na tarifa social, adotou-se a relação entre a TSA e a TRM (Tarifa Residencial Média). Para tanto, utilizou-se como amostra os 
dados de uma concessionária de grande porte em pelo menos um estado de cada grande região do Brasil. Utilizou-se também de informações obtidas da legislação e documentos das agências reguladoras de saneamento e das companhias de saneamento para identificar as metodologias adotas na classificação dos usuários e como se delimitam as condições de acesso em cada um dos casos.

\section{RESULTADOS E DISCUSSÃO}

Observou-se que as ações de promoção da TSA vigentes estão longe de alcançar a todos os municípios e sua população. Como apontam Santos (2020), Kuwajima et al. (2020) Brasil 2018; 2019), Santos e Santana (2020), o déficit de sistemas de água e esgotamento sanitário é mais grave: i) nos municípios mais pobres das regiões Norte e Nordeste; ii) na zona rural que depende de soluções isoladas e gestão comunitária; iii) onde não há empresas ou entidades municipais consolidadas de prestação de serviços. Em sistemas isolados, marcadamente nas regiões Norte e Nordeste e nos sistemas de saneamento rural, não há um conjunto de ações que garantam a estabilidade dos sistemas em situações de carestia de preços e de perda de renda, como ocorre na pandemia da Covid 19.

Os resultados obtidos mostram que: i) as iniciativas são recentes - em geral menos de 10 anos, com poucas exceções; ii) os governos estaduais geralmente arcam com a responsabilidade de instituir a TSA; iii) há recentes e importantes interferências das agências reguladoras na implantação e garantias da TSA (a exemplo de São Paulo e Minas Gerais); iv) as definiçõos de público-alvo, parâmetros de acesso, permanência e formas de monitoramento são muito distintas, e incompletas; v) o percentual estimado de redução identificado oscila muito - de 31\% (no DF, em 2019, que elevou o desconto, no final de 2020) a 72\% para determinado grupo e consumo, em São Paulo. O Quadro 1 apresenta a situação da TSA ou de medidas semelhantes a ela identificadas na amostra de um estado por região.

Quadro 1. Tarifa social da água ou sistema semelhante - exemplos de concessionárias por região e estado.

\begin{tabular}{|c|c|c|}
\hline Estado & $\begin{array}{l}\text { Relação } \\
\text { TSA/ TRM } \\
\left(\mathrm{R} \$ / \mathrm{m}^{3}\right)\end{array}$ & Destaque Regional \\
\hline Acre & 0,50 & $\begin{array}{l}\text { Cidade de Rio Branco, } 2017 \text {, até } 15 \mathrm{~m}^{3} \text { de água mais } 0,8 \times \text { preço do } \\
\text { esgoto, para carentes ou aposentados ou com Programa Bolsa Família } \\
\text { (PBF) ou Benefício de Prestação Continuada (BPC) e moradia de até } \\
40 \mathrm{~m}^{2} \text {. Consumidores monofásicos de energia até } 80 \mathrm{kwh} / \mathrm{mês} \text {, renda } \\
\text { até } 1 \text { salário mínimo (SM) por família. Redução de } 50 \% \text { na conta de } \\
\text { água e esgoto no valor da faixa } 0-10 \mathrm{~m}^{3} / \mathrm{mês} \text {. }\end{array}$ \\
\hline Ceará & 0,49 & $\begin{array}{l}\text { Companhia de Água e Esgoto do Estado do Ceará (Cagece) em } 2019 . \\
\text { Até } 10 \mathrm{~m}^{3} \text { de água e esgotos. Governo isentou até noventa dias devido à } \\
\text { Covid-19 - estimam-se } 338 \text { mil residências e } 1,5 \text { milhão de pessoas } \\
\text { beneficiadas pela TSA no estado. }\end{array}$ \\
\hline São Paulo & $0,28-0,48$ & $\begin{array}{c}\text { Companhia de Saneamento Básico do Estado de São Paulo (Sabesp), } \\
\text { 2019: TSA até } 10 \mathrm{~m}^{3} \text { o mesmo para a tarifa favela, para a situação de } \\
\text { São Paulo - base de cálculo de 70\% de água pela TSA, } 80 \% \text { de serviço } \\
\text { de esgotos e com "tarifa favela" em 30\%. }\end{array}$ \\
\hline Paraná & 0,31 & $\begin{array}{l}\text { Companhia de Saneamento do Paraná (Sanepar) em } 2018 \text { para imóvel } \\
\text { de até } 70 \mathrm{~m}^{2} \text {; consumo de água até } 10 \mathrm{~m}^{3} / \mathrm{mês} \text {; famílias com mais de } \\
\text { quatro pessoas e consumo superior a } 10 \mathrm{~m}^{3} / \mathrm{mês} \text { - considera consumo } \\
\text { de até } 2,5 \mathrm{~m}^{3} / \mathrm{mês} \text { por pessoa; renda da família de até meio SM por } \\
\text { pessoa ou de até } 2 \text { SMs para imóveis com até quatro ocupantes. }\end{array}$ \\
\hline
\end{tabular}




\begin{tabular}{|l|l|l|}
\hline Distrito & 0,69 & $\begin{array}{c}\text { Agência Reguladora de Águas, Energia e Saneamento do Distrito } \\
\text { Federal (Adasa) e Companhia de Saneamento Ambiental do Distrito } \\
\text { Federal }\end{array}$ \\
$\begin{array}{c}\text { Federal (Caesb), 2019, para residências até } 10 \mathrm{~m}^{3} / \mathrm{mês} \text { (esgoto }=85 \% \\
\text { da água) - mudanças em debate podem reduzir até } 70 \% \text { nas contas. }\end{array}$ \\
\hline
\end{tabular}

Legenda: TSA - Tarifa Social Média; TRM - Tarifa Residencial Média.

Fonte: adaptado de Santos (2020) - ados das agências reguladoras e de prestadoras de serviços de saneamento.

O volume consumido de referência por residência para acessar o benefício oscila entre $10 \mathrm{~m}^{3}$ e 25 $\mathrm{m}^{3}$, conforme o estado, o município, a condição específica e a opção política dos gestores das empresa/companhias do sistema de água. A escolha política de implementar a TSA e a definição dos seus parâmetros se repete nas UFs no que diz respeito à forma de operacionalizar e custear o benefício: geralmente estados e concessionárias, nem sempre com equilíbrio de tarifas. Isso indica a necessidade de se estabelecerem regras com responsabilidades do Estado e demais agentes neste tema, assim como as respectivas fontes, difusão dos custos e outras informações completas sobre os mecanismos, de modo a permitir avaliações a aperfeiçoamentos.

As características, evolução e situação atual do marco legal, de desafios operacionais e regulatórios, bem como de financiamento da TSA, são resumidas no Quadro 2. Como se pode notar, há uma série de dificuldades de implementação, uma vez que o tema não foi anteriormente prioritário no debate e nas políticas públicas. As mudanças na legislação têm focado a repartição de mercados estáveis de prestação de serviços de água, enquanto a TSA atende justamente os usuários de menor interesse no contexto da mercadoria água. Em termos de diretrizes, a legislação é bastante avançada, residindo lacunas nas fases de instrumentos, regulação dos serviços no âmbito executivo e pontos operacionais.

Quadro 2. Situação institucional e lacunas da TSA no Brasil segundo parâmetros selecionados.

\begin{tabular}{|c|c|c|}
\hline Parâmetros & Situação observada & Lacunas e dúvidas principais sobre a TSA \\
\hline Marco Legal & $\begin{array}{l}\text { A TSA se apoia no art. } 30 \text { da Lei } \\
\text { no } 11.445 / 2007 ; \\
\text { A Lei } 14.026 / 2020 \text {, que altera a } \\
\text { Lei } 11.445 / 2007 \text {, sinaliza, Art. } \\
23 \text { e outros, a possibilidade de } \\
\text { avanços por meio da regulação } \\
\text { (pela ANA e Agências); }\end{array}$ & $\begin{array}{l}\text { Não uniformidade na garantia do direito; } \\
\text { A Lei 14.026/2020 pouco avança na garantia } \\
\text { do direito (pois traz diretrizes, não } \\
\text { obrigações sobre água e direito humano); } \\
\text { Qual é de fato a autonomia e poder das } \\
\text { agências reguladoras para tratar o tema? }\end{array}$ \\
\hline $\begin{array}{l}\text { Operacionais } \\
\text { e Regulatórios }\end{array}$ & $\begin{array}{c}\text { Estados, municípios e } \\
\text { prestadores estabelecem modelos } \\
\text { e regras operacionais onde há } \\
\text { TSA ou medida semelhante; } \\
\text { Agências reguladoras, } \\
\text { recentemente, passam a exigir ou } \\
\text { pactuar a TSA e parte de seus } \\
\text { parâmetros }\end{array}$ & $\begin{array}{c}\text { Grande dependência das companhias } \\
\text { estaduais (na implementação, modelagem, } \\
\text { operação e monitoramento da TSA, } \\
\text { inclusive custos); } \\
\text { Faltam instrumentos que garantam } \\
\text { transparência para a fiscalização e controle } \\
\text { pela sociedade; } \\
\text { Dúvidas sobre a efetividade de alcance do } \\
\text { público-alvo (está chegando exatamente a } \\
\text { quem precisa?); } \\
\text { Dificuldade de se estabelecer regras para } \\
\text { saída de beneficiários da TSA (ex.: pelo }\end{array}$ \\
\hline
\end{tabular}




\begin{tabular}{|c|c|c|}
\hline & & $\begin{array}{l}\text { aumento do consumo? Pelo aumento da } \\
\text { renda? Por tempo de permanência?) }\end{array}$ \\
\hline Financiamento & $\begin{array}{l}\text { A PNSB (e a Lei 14.026/2020, } \\
\text { que a modificou) prevê } \\
\text { investimentos e custeio do } \\
\text { saneamento via tributos (recursos } \\
\text { da União, estados, Distrito } \\
\text { Federal e municípios) e da tarifa } \\
\text { (arrecadação das concessionárias } \\
\text { de água e esgotos). Estes últimos } \\
\text { sustentam a TSA. A União } \\
\text { custeia situações restritas, como } \\
\text { no Programa Água Doce. }\end{array}$ & $\begin{array}{l}\text { Indefinições de responsabilidades e fontes } \\
\text { de financiamento para cada nível de governo } \\
\text { e demais agentes responsáveis. Por exemplo: } \\
\text { a União deve custear parte da TSA (tese de } \\
\text { direito humano)? Estados devem ter leis } \\
\text { para custear uma parcela? As concessões } \\
\text { devem prever que nível de custeio via tarifa? } \\
\text { Deve haver fundo específico? (Este caberia } \\
\text { a que nível de governo?). }\end{array}$ \\
\hline
\end{tabular}

Fonte: elaborado pelos autores.

Adicionalmente à PNSB e às normas posteriores a ela, os Decretos $n^{\circ} 10.588$, de 24 de dezembro de 2020 e $\mathrm{n}^{\circ}$ 10.710, de 31 de maio de 2021, trazem aspectos técnicos e novas diretrizes para o apoio financeiro da União aos municípios pobres e à população de baixa renda. Entretanto, as barreiras previstas podem dificultar tanto a expansão de sistemas quanto a manutenção de preços acessíveis. Por outro lado, os mencionados decretos são base importante para o estabelecimento de metas e produção de indicadores, envolvendo as agências reguladoras, permitindo que a sociedade monitore desafios e avanços na cobertura de água, do esgotamento sanitário e da TSA.

De acordo como o MDR, mecanismos do tipo TSA alcançam apenas 5\% dos usuários dos serviços de água e esgotos. Contudo, não foi possível precisar o público-alvo, em razão das diferentes regras adotadas. Registram-se indefinições, falta de esclarecimentos e até barreiras que impedem tanto a definição dos critérios de enquadramento e de saída dos usuários beneficiários da condição de público-alvo da TSA. Em geral, esse público-alvo é identificado e a tarifa calculada tendo em conta: i) as pessoas de baixa renda, segundo registros do Programa Bolsa Família (PBF) e/ou no Cadastro Único para Programas Sociais (CadUnico); ii) o tamanho, condições e local da residência; iii) foco em moradores do meio urbano; e iv) o consumo mensal de água e o volume lançado de esgotos.

Durante a Pandemia Covid 19 (2020 e 2021, principalmente) os estados e o DF implementaram medidas de garantia de serviços de água e esgotos a esse público-alvo, inclusive com aumento de benefícios mesmo onde já havia TSA. Além dos subsídios estaduais e municipais e da proibição de corte no fornecimento de água, elevou-se consensos e evidenciou-se que órgãos de promoção da Justiça, estados e agências reguladoras têm ferramentas (marco legal e seus instrumentos), capacidades e oportunidade de defender a água como direito humano. Os impactos e custos desse momento devem ser analisados tendo em vista o aprendizado para o aperfeiçoamento da TSA.

\section{CONCLUSÕES}

Embora em alguns aspectos tratem de regras gerais, verificou-se que o conjunto das normas vigentes no Brasil traz os elementos-base para o aperfeiçoamento da TSA e das medidas semelhantes adotadas em diversas localidades. Isso inclui mecanismos e instrumentos que suportam atuações de Agências Reguladoras, Ministério Público e Justiça, no reconhecimento do direito à água. A governança e a gestão participativas em foros deliberativos sobre saneamento são essenciais para o fortalecimento da fiscalização, bem como para o planejamento e o alcance de consensos acerca do perfil, do custeio e das regras faltantes sobre a TSA. 
A legislação brasileira, com destaque para a Lei no 11.445/2007 e suas atualizações (como a Lei 14.026/2020 - denominado Novo Marco do Saneamento) admitem, como visto, subsídios tarifários e não tarifários para obras e ações de gestão. Contudo, há necessidade de maior transparência operacional e controle da sociedade sobre as iniciativas, de modo a garantir o acesso a todos que dele necessitam. Além disso, embora importante, o foco em investimentos nas infraestruturas de municípios e usuários sem capacidade ou de baixa escala econômica, não pode ser pretexto para excluir bairros periféricos da maioria dos municípios brasileiros, mesmo onde há bons índices de cobertura, pois se constata que também nelas há cidadãos sem os serviços de saneamento.

Para que a TSA e outras soluções com perfil semelhante sejam edificadas no Brasil é primordial que se admita o direito à água como direito humano. Nessa condição, as responsabilidades dos agentes do setor de saneamento (concessionárias, agentes reguladores, municípios) e também do Estado não estão de todo claras quanto a aspectos regulatórios, financeiros e operacionais, como visto. Há a necessidade de maior articulação entre instituições, comunidades e academia, para difundir a oportunidade do poder público, concessionárias, agentes reguladores e órgãos de promoção da Justiça atuarem na defesa da água como direito, indo além das iniciativas atuais, ainda isoladas.

\section{BIBLIOGRAFIA}

ARAÚJO, F. C.; BERTUSSI, G. L. Saneamento básico no Brasil: estrutura tarifária e regulação. Revista Planejamento e Políticas Públicas, n. 51, p. 165-202, 2018.

BRASIL. Ministério do Desenvolvimento Regional. Plansab - Plano Nacional de Saneamento Básico, Revisão 2017-2019. Brasília: SNS/ MDR, 2019. 240 p.

. FUNASA - FUNDAÇÃO NACIONAL DE SAÚDE; UFMG - UNIVERSIDADE FEDERAL DE MINAS GERAIS. PNSR em construção: Programa Nacional de Saneamento Rural. [s.1.]: Funasa/UFMG, 2018.

HELLER, L.; BUSS, D. F.; BARRAQUÉ, B. Água e saúde coletiva: uma agenda em atualização (Editorial). Ciência \& Saúde Coletiva, 21(3): 658, 2016

HULTON, G.; WORLD HEALTH ORGANIZATION. Global costs and benefits of drinking-water supply and sanitation interventions to reach the MDG Target and Universal Coverage. Geneva: WHO, 2012. $67 \mathrm{p}$.

KUWAJIMA, J. I.; SANTOS, R. R.; FECHINE, V. M.; SANTANA, A. S. Saneamento no Brasil: proposta de priorização do investimento público - Texto para Discussão $n^{\circ}$ 2614. Brasília: IPEA, 2020

SANTOS, G. R. Estado e Saneamento: Sugestões de Apoio à População Carente Durante e Após a Pandemia da Covid-19. Nota Técnica n ${ }^{\circ} 18$, jul. 2020. Diretoria de Estudos e Políticas Regionais, Urbanas e Ambientais - Dirur/IPEA. Brasília: IPEA, 2020. Disponível em: https://www.ipea.gov.br/portal/index.php?option=com_content \&view=article\&id=36258\&Itemid=7

SANTOS, G. R.; SANTANA, A. S. Gestão comunitária da água: soluções e dificuldades do saneamento rural no Brasil - Texto para Discussão nº 2601. Brasília: IPEA.

WHO - WORLD HEALTH ORGANIZATION. Global health risks: mortality and burden of disease attributable to selected major risks. Geneva: WHO, 2009. 62 p. 